\title{
¿Y tú, das pecho o biberón? \\ Narrativas, identidad de género \\ y lactancia materna
}

\author{
ANA PAULINA GUTIÉRREZ MARTÍNEZ
}

Con base en una investigación cualitativa sobre lactancia, género y narrativas identitarias en Morelos y la Ciudad de México, dentro y fuera de las redes sociales en internet, se reflexiona sobre algunas narrativas de las mujeres entrevistadas y sus experiencias en torno a la lactancia materna. Se analiza la relación entre identidad de género y lactancia materna por medio de dos dimensiones: la emocional y la de administración del tiempo y los cuidados. El texto se basa en el análisis de 16 entrevistas y de imágenes que circulan en grupos de mujeres en Facebook, que promueven la lactancia o que alimentan a sus bebés con biberón.

PALABRAS CLAVE: género, identidad, lactancia materna, emociones, tiempo

\section{Do You Breastfeed or Bottle? Narratives, Gender Identity and Breastfeeding}

Based on qualitative research about breastfeeding, gender and identitary narratives in Morelos and Mexico City, online and offline, this paper focuses the analysis on some of the narratives of interviewed women and their experiences on breastfeeding. The analysis is about the relation between gender identity and breastfeeding, following two dimensions: emotions and time and care administration. The text is based on the analysis of 16 interviews and images shared on Facebook groups conformed by women who promote breastfeeding or women who feed their children with bottle.

KEYWORDS: gender, identity, breastfeeding, emotions, time

Ana Paulina GutiérRez Martínez

Programa Interdisciplinario de Estudios de Género, Centro de Estudios Sociológicos,

El Colegio de México, México apgutierrez@colmex.mx 


\section{Introducción}

Qué relación tiene la identidad de género con la lactancia materna? ¿En qué

forma la lactancia materna constituye a las mujeres de ciertas sociedades en sujetos sociales? ¿Qué elementos entran en juego en la decisión de dar o no dar leche materna? Éstas son algunas de las preguntas que guían este texto, en el que se intenta reflexionar sobre la lactancia materna, una de las experiencias corporales y emocionales que atañe a las mujeres, la lleven a cabo o no.

La lactancia materna puede ser entendida sólo como un proceso biológico que consiste en que los cuerpos de las mujeres produzcan leche y la proporcionen a sus crías como cualquier mamífero. Sin embargo, en este artículo se parte de la idea de que la lactancia materna es un proceso social que involucra las experiencias corporales de las mujeres, sus emociones y sus expectativas en torno a un momento particular de la crianza. Asimismo, la lactancia se relaciona con las representaciones de sus cuerpos, de la maternidad y de ser mujer. Esto lleva a pensar en la posible relación entre identidad de género y lactancia materna. El estudio socioantropológico de la lactancia como una práctica social aporta información relevante y novedosa para comprender algunas de las formas en las que opera el orden de género en contextos contemporáneos.

En México, la conversación pública sobre lactancia se centra sobre todo en los beneficios que tiene para la criatura recién nacida y en los bajos niveles de lactancia materna exclusiva en los primeros seis meses de vida del menor, de tan sólo 14.4\% (Gutiérrez et al., 2012). En el mismo tenor se trata de promover los beneficios que la lactancia materna tiene para la madre, desde bajar de peso hasta prevenir el cáncer de mama. Esta conversación se entabla principalmente entre instituciones de salud pública, usuarias de diferentes sistemas sanitarios y organizaciones promotoras de la lactancia materna.

Por su parte, la discusión académica en distintos contextos de investigación se divide, a grandes rasgos, en dos temas generales que se engarzan. El primero es la 
relación entre los bajos niveles de lactancia, la falta de promoción de la lactancia por parte de las instituciones de salud y los médicos, la falta de habilidades y "adiestramiento" de las mujeres lactantes, y los beneficios físicos, psicológicos y sociales de la lactancia materna para el infante y la madre a corto y largo plazo (Boswell-Penc, 2006; González et al., 2014; González et al., 2013; Gorrita et al., 2014b; Leon-Cava et al, 2002; McTeer, 2012).

El segundo, recurrente en algunos estudios, se refiere a las condiciones desfavorables para las mujeres que desean llevar a cabo la práctica de la lactancia. En el campo de la salud y la medicina, estas cuestiones adversas se relacionan con padecimientos físicos o psicológicos y se mencionan brevemente las cuestiones laborales, sin profundizar demasiado en ello (Gorrita et al., 2014a; Pino et al., 2013). Algunas otras investigaciones explican las condiciones adversas en relación con la falta de lactarios en las sedes laborales o la dificultad de los desplazamientos entre el lugar donde labora la mujer y el lugar donde se encuentra el infante, o la enorme inversión de tiempo que implica "sacarse la leche" y almacenarla en forma adecuada (Lubold y Roth, 2012; Lucas y McCarter-Spaulding, 2012). También se analiza el papel de los bancos de leche o lactarios domiciliarios en el abandono o continuación de la lactancia materna al momento de regresar al trabajo (Núñez, Franco y Labrador, 2017). Otra situación desfavorable es la vigilancia que las mujeres perciben en relación con sus cuerpos en los espacios públicos, donde a veces la lactancia se prohíbe de manera velada, lo cual pone sobre la mesa el tema de la sexualización de los cuerpos de las mujeres y el control sobre éstos (Bartlett, 2005; Dowling, Naidoo y Pontin, 2012; Gatens, 2003; Hurst, 2012).

Sin embargo, existe poca investigación sobre las experiencias subjetivas de las mujeres en torno a la lactancia materna, ya sea que la practiquen o no. Es decir, algunas mujeres, si bien no experimentan la práctica de la lactancia, se relacionan en cambio con los discursos sobre ésta, así como con el deber ser y las representaciones sobre el cuerpo, la maternidad y el ser mujer (Bartlett, 2005; Wolf, 2011).

Por lo anterior, me atrevo a pensar que existe una relación entre la lactancia materna como práctica social $-\mathrm{y}$ como discurso social— y los procesos de configuración de la identidad de género de algunas mujeres (Koerber, 2013; Wolf, 2011). Dicha relación sirve para situarse en el mundo social y distinguirse entre mujeres, tanto madres como no madres, y también posicionarse en relación con otros sujetos sociales (Bourdieu, 2002). Este proceso de diferenciación identitaria de las mujeres forma parte del orden social y de género de las sociedades contemporáneas, y trae consigo algunos conflictos dignos de documentarse y estudiarse desde las ciencias sociales, como la relación entre las emociones, la experiencia de la lactancia, su idealización y obligatoriedad.

La maternidad es una representación de lo femenino que marca la identidad subjetiva y la vida de las mujeres, ya sea que decidan ser madres o no. Es un elemento presente en los procesos de configuración de la identidad de género: ser o no ser madre contribuye a las formas en las que las mujeres habitan el mundo, se expresan y establecen relaciones sociales. La lactancia materna es un elemento que acompaña este acontecimiento de la vida de algunas mujeres, a quienes se les imputa la alimentación y crianza de los hijos como obligación casi irrenunciable, sobre todo con base en la idea de la existencia de lo que se ha llamado "instinto maternal". A su vez, es una práctica que se ha idealizado como algo natural, y por lo tanto, se da por sentado que no tiene por qué ser doloroso, incómodo o molesto para ellas.

La lactancia materna, en sus diversas formas, es un elemento del proceso de crianza que cobra relevancia para el estudio de la identidad de género, ya que funciona como marcador normativo en la valoración, no sólo de ser madre, sino de ser "una buena madre", entre grupos de mujeres que comparten la 


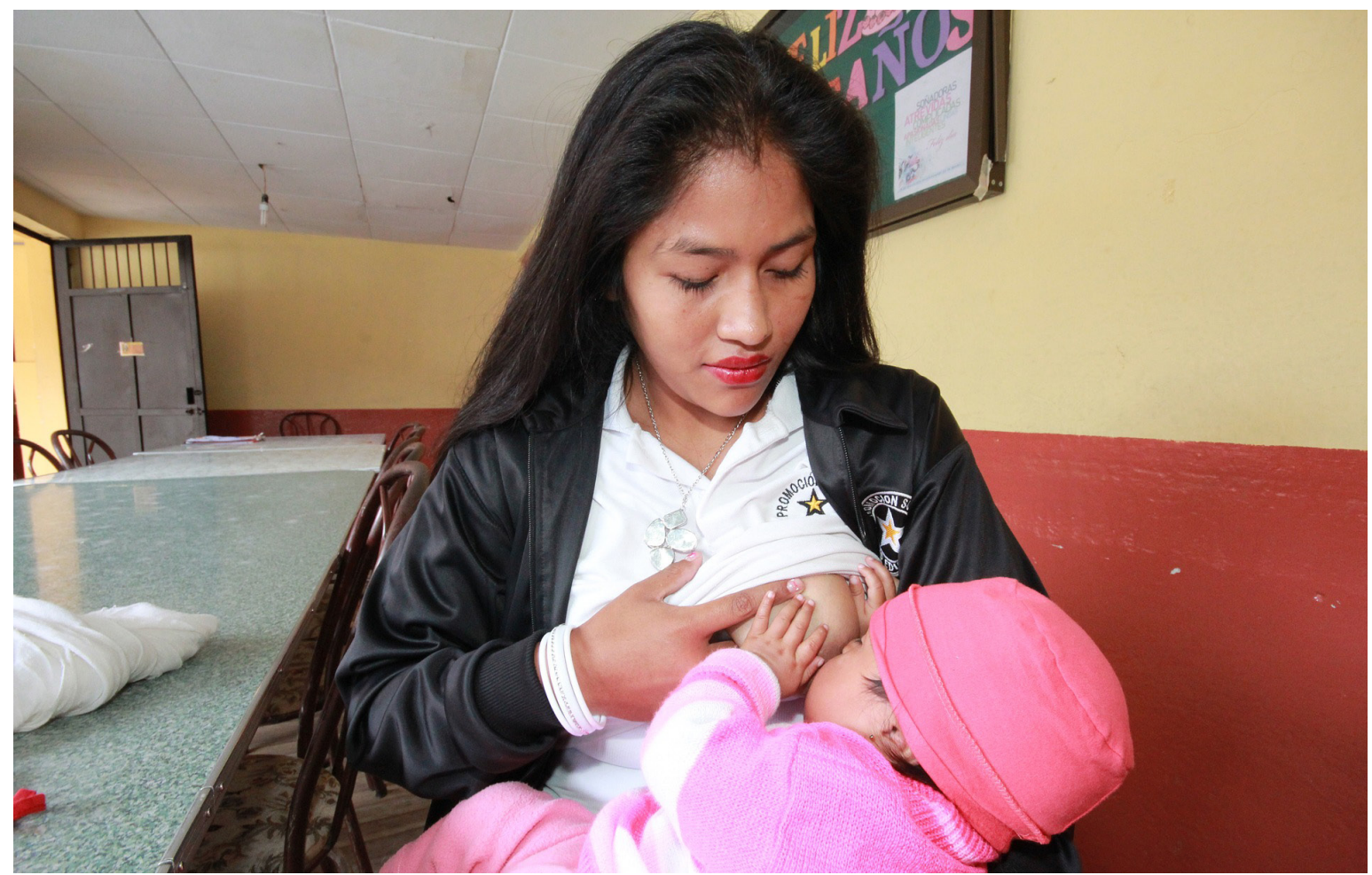

CARLOSALBERTONY/PIXABAY - Mujer amamantando a su hija.

experiencia. ${ }^{1}$ Esta experiencia hace observables los significados asignados al cuerpo de las mujeres. La demanda social para que esta práctica se adecue a normas relacionadas con el espacio público permite observar y analizar las formas en las que el orden de género se encarna en las personas e instituciones (Cano, 2009; Dowling, Naidoo y Pontin, 2012; Gatens, 2003; Gutiérrez, 2015; Hurst, 2012).

Planteo las identidades de género como procesos flexibles que se construyen a lo largo de la vida de las personas en articulación con otras identidades, como clase social, etnia, raza, generación, nacionalidad, etc., dependiendo del contexto sociohistórico. La identidad, en términos más generales, alude a un sentimiento ontológico de la persona, es decir, a las formas en las que se concibe la existencia y el ser de determinadas maneras y no de otras. La identidad sitúa a la persona en la trama social, de acuerdo con las jerarquías de cada forma de organización que atraviesa a dicha persona (Boas, 1941; Bourdieu, 2006; Chávez y Guido-Dibrito, 1999; Fearon y Laitin, 2000; Giddens, 1991; Giménez, 2000; 2009; Sanders, 2002; Stryker, 2008; Valentine, 2014). En este caso, me centro en la identidad de género de las

Existen diferentes tipos de lactancia: lactancia materna exculsiva, cuando la leche materna es el único alimento que recibe el infante; lactancia artificial, cuando la alimentación del infante se realiza con fórmula láctea; lactancia mixta, cuando se combinan la leche materna y la fórmula láctea para alimentar al infante; lactancia materna complementada, cuando la leche materna se complementa con alimentos sólidos o líquidos no lácteos; lactancia mixta complementada, cuando el infante recibe leche materna, fórmula láctea y otros alimentos sólidos o líquidos; lactancia artificial complementada, cuando se alimenta al infante con fórmula láctea y alimentos sólidos o líquidos (Gorrita et al., 2015). 
mujeres con quienes se llevó a cabo la investigación, es decir, en la experiencia de ser o existir como mujer en un contexto sociohistórico determinado, mediado por la lactancia materna.

Entiendo por género una forma de organización social que jerarquiza a las personas, sus identidades y las relaciones sociales, de acuerdo con la diferencia de los cuerpos en relación con la biología de la reproducción humana y las formas del deseo erótico. Dicha organización es binaria y heteronormativa, porque su lógica se basa en la consideración de la matriz heterosexual como norma para las relaciones sociales, y por lo tanto, para la configuración de las identidades de las personas y sus prácticas (Gutiérrez, 2015). El género está compuesto por cuatro subconjuntos organizativos: las representaciones simbólicas, los conceptos normativos, las instituciones sociales y organizaciones, y las identidades subjetivas (Scott, 2008). Un elemento importante del género es su carácter performativo, por el cual se constituye la identidad que se supone ser. El género funciona como un ritual que consigue su efecto por medio de la naturalización de un cuerpo, entendido como una unidad material, situada histórica y socialmente, llena de significados que hacen que dicha naturalización se sostenga culturalmente. Este ritual opera también por medio del discurso, al lograr los efectos ontológicos de las categorías de género (Butler, 2007; Gutiérrez, 2015).

Las narrativas utilizadas por las mujeres para hablar de sus experiencias, durante las entrevistas y en los diversos grupos de Facebook, me permitieron acceder a sus representaciones de la lactancia y algunas de sus emociones, y por ende, analizar su relación con la identidad de género. Por medio de estas narrativas, se observan las formas en las que la organización social por género se encarna en las mujeres y se despliega en las interacciones cotidianas que se mueven de manera inevitable en juegos de acercamiento y distanciamiento identitarios. Las decisiones sobre su cuerpo y sobre la crianza colocan a las mujeres en sitios diferenciados en el orden de género, clase y raza ${ }^{2}$ que se negocian en la vida íntima, pública y cotidiana.

\section{Estrategia metodológica}

Este texto es producto de una investigación exploratoria de corte cualitativo. Me valí del método etnográfico y utilicé técnicas como la observación y la entrevista. También hice uso de la red sociodigital Facebook como una herramienta para establecer el rapport, organizar la cita para la entrevista y observar la circulación de narrativas visuales sobre la lactancia, así como los comentarios sobre estas últimas, que compartía la mayoría de mis interlocutoras. Estos materiales circulaban tanto en sus perfiles individuales - biografías - como en los grupos y páginas dedicados a la lactancia materna o la lactancia con biberón. Aquí me referiré a dos grupos y hablaré sólo de cuatro imágenes que permiten problematizar la relación de la identidad de género con las emociones y la lactancia. Sin embargo, existen otros grupos con características parecidas y circula una gran cantidad de imágenes susceptibles de ser analizadas por su contenido simbólico y por la movilización de los discursos de género que producen.

Los dos grupos solicitaban a las mujeres llenar un breve cuestionario para ser aceptadas como miembros. Estos dos grupos eran los más dinámicos, es decir, los que compartían más información y

2

La categoría de raza opera en el campo de investigación mediante la configuración de prácticas y representaciones de género. No me refiero a la existencia en sí de razas humanas sino a los significados que las mujeres identifican y asocian con el origen de las personas y el color de piel, principalmente. La distinción más notoria se hace entre "india" y "mujer de ciudad", y opera en un registro distinto al de la clase social, aunque en ciertos momentos se relacionan. 
tenían una cantidad considerable de respuestas por medio de reacciones y comentarios. También elegí un grupo pro lactancia y uno de madres que no amamantan o practican la lactancia mixta. En ambos casos llené el cuestionario haciendo explícito mi interés en el tema para la investigación social. Fui aceptada en los dos, y mi papel se limitó a observar sin participar en las publicaciones que se hacían en estos grupos. Los materiales gráficos seleccionados para este texto son algunos de los que causaron mayor debate en los comentarios y me permiten reflexionar sobre la relación entre lactancia materna, emociones e identidad de género.

En cuanto a los criterios de selección para las participantes del estudio, se buscó que tuvieran entre 20 y 45 años de edad, que tuvieran uno o más hijos de entre cero y cuatro años de edad, que fueran usuarias de Facebook y que quisieran participar de manera voluntaria en la investigación.

Se llevaron a cabo 16 entrevistas semiestructuradas con base en una guía flexible que abordaba distintos componentes temáticos sobre los cuales se trabajó en el análisis de contenido. Todas las entrevistas se grabaron y transcribieron para su análisis. También se tomaron notas durante cada una de las entrevistas y se agregaron a las observaciones de campo registradas en el diario de campo. Para resguardar las identidades de las participantes, se utilizan seudónimos tanto para los grupos de Facebook a los que hago referencia como para las entrevistadas.

\section{Narrativas sobre lactancia}

Las mujeres narran experiencias muy diversas en relación con la lactancia materna. Algunas han decidido no amamantar, otras lo han hecho por poco tiempo y otras mantienen la lactancia materna por tiempos prolongados — dos años o más-. Estas experiencias fueron narradas a partir de su primer contacto con las instituciones médicas y están marcadas, en general, por emociones negativas, como dolor, enojo, culpa y tristeza. Sólo dos de las 16 entrevistadas hablaron del parto como un suceso gozoso, que si bien implicaba dolor, no estaba mediado por el maltrato de otras personas.

Una vez que ha terminado el parto y que comienza el proceso necesario y casi inmediato de alimentación del infante, las expectativas de las mujeres sobre la maternidad comienzan a moldear sus decisiones y la relación que establecen con sus hijos o hijas, con los espacios que habitan y con sus propias trayectorias de vida. Las emociones también dan forma a la experiencia de ser madre y de vinculación con los hijos. Mediante sus propios procesos de reflexión, las mujeres con quienes trabajé en la investigación adquirieron herramientas para construir su experiencia como algo gozoso, obligatorio, temporal o definitivo, según sea el caso.

En este análisis, la relación entre ser mujer y madre, y la lactancia materna, se observa a partir del deber ser y sus representaciones. De acuerdo con Joan Wallach Scott (2008), éstos son dos de los subconjuntos del género que las mujeres movilizan en sus narrativas sobre el cuidado del infante, y se asocian a dos elementos, las emociones y la administración del tiempo y los cuidados.

Como ya mencioné, he decidido utilizar algunos insumos de dos de los grupos de Facebook y algunas de las entrevistas cara a cara con mis interlocutoras. A continuación, hago una breve caracterización de estos componentes.

\section{LOS GRUPOS}

El acercamiento a los grupos de Facebook fue útil para observar algunas representaciones sobre la maternidad y las mujeres que circulaban en esta red social. La conformación de los grupos me daba ya una idea de un proceso identitario que no sólo expresaba y reunía a mujeres con ciertas características y 
experiencias en común, sino que dejaba fuera a las que no compartían algunas prácticas o discursos sobre la lactancia y otros elementos de la crianza. Ambos grupos tienen, en la parte superior de su perfil de Facebook, un marco normativo que establece las reglas para ser miembro.

En "Consejeras de lactancia", un grupo cerrado, ${ }^{3}$ las reglas principales estipulan que es necesario identificarse cuando se hace una publicación; no se permiten recomendaciones desactualizadas o contrarias a la Organización Mundial de la Salud ni recomendaciones de medicamentos. También se establece que no es un grupo para compartir experiencias particulares sino ayuda correcta y actualizada, y de no ser así, se borrará el comentario o la publicación. Sin embargo, la mayoría de las publicaciones son sobre experiencias de las mujeres que han decidido amamantar, desde dudas acerca de diferentes asuntos relacionados con la crianza hasta "desahogos" — como ellas los llaman— por los comentarios que reciben en torno a cuándo terminarán de dar pecho.

En "Madres de mamila", un grupo secreto, ${ }^{4}$ se establece que su función es de apoyo a las madres que, por cualquier razón, han optado por dar biberón o lactancia mixta. Se deja muy claro que cualquier comentario contra este método de alimentación ameritará expulsión inmediata. También se prohíbe recomendar medicamentos y se insiste en no juzgar las experiencias de ninguna participante. Una de sus reglas prohíbe hablar de otros grupos, es decir, hacer comparaciones con grupos dedicados a promover la lactancia materna, y se advierte que este tipo de publicaciones serán borradas. ${ }^{5}$

\section{LAS ENTREVISTAS}

Como ya se explicó, se diseñaron entrevistas semiestructuradas. La mayoría de mis interlocutoras se acercó a mí para participar en la investigación.
Querían contarme su experiencia. Parecía que nunca habían hablado de este proceso con lujo de detalle y pensaban que hacerlo era una buena idea. Así, acordamos un lugar en el que ellas se sintieran cómodas, ya fuera con su bebé o a solas. De esta manera, se producían condiciones diferentes para cada conversación, lo que aportaba información relevante durante la observación. Algunas de mis interlocutoras se encontraban en los primeros meses de lactancia materna, mientras que otras la habían vivido hacía algunos años. Esta diferencia permitió apreciar los pormenores de los procesos de reflexión que las mujeres construyen a lo largo del tiempo.

Las entrevistas tuvieron una duración aproximada de una hora u hora y media. La guía que elaboré, y que trataba de llevar de manera amable, sin que se sintiera como un cuestionario sino como una plática relajada, comenzaba por pedir información sobre el bebé, lo que propiciaba que ellas se sintieran cómodas y contentas. Esto me parece relevante porque el proceso de lactancia, en particular, está íntimamente ligado a las emociones. Una vez que me presentaban a su hija o hijo por medio de la narrativa, les pedía que me contaran cómo había sido la llegada del bebé a este mundo. Para ese momento,

3

Esta modalidad de grupo de Facebook consiste en que cualquier persona puede buscar el grupo y ver quién lo administra, pero sólo los miembros pueden ver quién pertenece a éste y lo que se publica en él.

4 Esta modalidad de grupo de Facebook consiste en que sólo los miembros pueden ver el grupo, quién pertenece a él y lo que se publica ahí.

$5 \quad$ En ambos grupos es relevante la presencia de imágenes sobre las tecnologías de cada forma de crianza en particular. En "Consejeras de lactancia" hay muchas fotografías e información sobre sacaleches. En "Madres de mamila" abundan las imágenes de fórmulas y complementos, así como de biberones. Aún se puede profundizar en este tema, sobre todo en relación con la manera como entendemos lo natural versus lo artificial en las sociedades contemporáneas, y esto también constituye a las mujeres en tanto sujetos generizados. 
había ya una conexión en el diálogo que permitía que mis interlocutoras se expresaran con confianza $\mathrm{y}$ dieran detalles.

A partir de entonces, las emociones y la administración del tiempo en su vida cotidiana formaban parte fundamental de la conversación. A continuación, presento algunos de los resultados y reflexiones, divididos con base en estos dos aspectos y en la información de grupos y entrevistas.

\section{EMOCIONES}

En este trabajo, las emociones se entienden como prácticas culturales y no como estados psicológicos. Dichas prácticas son configuradas socialmente por medio de circuitos afectivos que suceden en las interacciones entre personas. También se considera la propuesta de entenderlas como acción o inacción, y por lo tanto, como productoras de realidades sociales (Ahmed, 2015). Así, las emociones marcan los espacios, delimitan las experiencias identitarias y distinguen a los sujetos sociales.

Las emociones que aparecen en las narrativas de mis interlocutoras son variadas y se van transformando a lo largo del proceso de crianza. La mayoría comienza por reconocer un estado de ansiedad, sea por el parto o la cesárea, que algunas de ellas resolvieron con métodos de meditación o técnicas de respiración y manejo del dolor que aprendieron durante el embarazo. Sin embargo, no todas contaban con estos recursos y algunas se enfrentaron al maltrato de los médicos y enfermeras en los hospitales, lo que aumentó su ansiedad, les produjo miedo, y en algunos casos, una seria sensación de vulnerabilidad que marcó sus vidas y el recuerdo del nacimiento de sus hijos. En estos casos, la ansiedad y el miedo, en términos de Ahmed (2015), propiciaron su inacción o su decisión de "dejarse llevar" por el personal médico:
Yo llegué al hospital con mucho miedo porque era mi primer hijo. Me aislaron en un cuarto. Le dije a la enfermera que quería hacer del baño y me dijo que no podía. Los dolores eran muy fuertes por el parto y porque quería defecar. Siento que me desmayé dos veces porque no me acuerdo cuándo me hice del baño (entrevista con Rubí, Cuautla, Morelos, marzo de 2018).

Yo hice todo por el bien de la niña. Me hice a la idea de que tenía que hacer lo que los médicos y las enfermeras decidieran por el bien de mi hija (entrevista con Lucía, Ciudad de México, abril de 2018).

En este mismo escenario, en muchos casos aparece la sensación de impotencia al darse cuenta de que la lactancia, concebida como algo natural, no era fácil de lograr. En el contexto de maltrato hospitalario, las mujeres se encontraban sin recursos para comenzar la lactancia con tranquildad. Las enfermeras hacían comentarios que aludían al carácter supuestamente obvio y natural de la lactancia - “ipégueselo, pégueselo!"hacerlo en realidad. Esto causaba mucha incomodidad en mis interlocutoras. Muchas de ellas expresaron, con distintas palabras, que la lactancia tiene "toda una técnica que no es natural y que no se enseña a las mujeres" (entrevista con Romina, Ciudad de México, mayo de 2018).

Todas mis interlocutoras reconocen que no sabían hacerlo. Algunas de ellas, dos de 16, tuvieron suerte y no sufrieron dolor porque la forma del pezón, la cantidad de leche que producían y los recursos de información con que contaban les permitieron una lactancia relativamente fácil y rápida. El resto describe el dolor en los pezones como "navajas" y la lactancia como "una tortura", debido al dolor, la falta de descanso y la continuidad de la succión en los pezones, además del sentimiento de culpa por no producir suficiente leche, de acuerdo con los 
estándares que la Liga de la Leche, ${ }^{6}$ las enfermeras, las amigas, los libros sobre el tema o la familia les marcaban. Las emociones en torno a esta experiencia corporal eran de impotencia, enojo, culpa y hartazgo:

Pues me trataron como tonta. Primero, apenas me enseñaron a la niña y se la llevaron. Luego, yo tenía sentimientos encontrados porque, la verdad, estaba tan cansada que sí quería que se la llevaran. Me siento tan mal de decirlo, pero pues ya lo dije [risas]. Me eché una "jetita" por fin, ${ }^{7}$ ignorando la culpa, y de repente llega la pinche enfermera y me prende la luz con unos gritos que hizo llorar a la niña. Yo sentía mucho rechazo porque imagínate que estás cansada, te duele todo y además te están metiendo mano con un molusquito que no te puedes acomodar y que te babea y te llora en el pezón. Horrible. La verdad. Nunca logré disfrutarlo y eso que después de los regaños, el cansancio y todo, era una vaca. No tuve problemas, pero si no fuera por la culpa que sentía, le hubiera dado fórmula y estaría igual de grandota y feliz mi niña. El baño, en cambio, ese sí que no lo cambio por nada (entrevista con Ana, Tepoztlán, Morelos, abril de 2018).

Era una tortura. Como si tuvieras navajas en los pezones. Por más que hacía, no lograba que dejara de lastimarme. Cada vez que la oía llorar, lloraba yo porque ya tocaba otra vez la tortura (entrevista con Magda, Tepoztlán, Morelos, marzo de 2018)

Yo sí quería amamantar. Es lo que crees que debe ser. Lo natural. Pero no me salía leche. Y todo mundo chinga con que a todas nos sale leche y pues no. Y el niño lloraba. Y en el hospital le dieron la fórmula y después ya fue más difícil. Yo le daba lo que me salía. Pero resultó ser alérgico a la proteína de la leche y pues tuvo que tomar una fórmula especial (entrevista con Gabriela, Ciudad de México, mayo de 2018).
En estas narrativas se observa que la culpa es el motor para la acción. Es decir, la culpa por no dar a la cría lo que se considera necesario para su bienestar es tan grande, que lleva a estas mujeres a aguantarse el dolor y la incomodidad. Una de ellas lo reconoce y piensa en retrospectiva que, si no hubiera sentido culpa, no hubiera amamantado y todo estaría bien. En la narrativa de la interlocutora que no amamantó aunque era su deseo, se nota una molestia cuando recuerda que recibió comentarios que aseguraban que todas las mujeres producen leche. Para ella fue una enorme frustración no poder amamantar a su hijo.

En relación con lo anterior, en los grupos pro lactancia materna con frecuencia circulaba una imagen que condensa la idea de que "todas las mujeres pueden amamantar”, muy utilizada para promover la lactancia, tanto por organizaciones como por mujeres en redes sociodigitales, y que muchas veces sirve de sostén a este argumento. La imagen invita a persistir en la lucha para lograr y mantener la lactancia materna a pesar de las dificultades de los primeros momentos, aunque duela y parezca que el infante no está satisfecho, o que otras personas insistan en alimentarlo con fórmula láctea (véase la imagen 1).

La Liga de la Leche es una organización fundada en 1956 en Estados Unidos, con sede en 85 países. En México se fundó en 1972 y su objetivo es promover y apoyar la lactancia materna "con un estilo de crianza que valora la maternidad". Uno de sus principios es que la lactancia propicia la comunicación y la unión familiar, ya que "el bebé tiene la misma necesidad de ser alimentado como de estar con su madre" (véase: <https://laligadelaleche.org.mx/IIImx/>). La Liga de la leche tiene una gran influencia en organizaciones más pequeñas que promueven la lactancia y en algunas mujeres que están por parir o están empezando la lactancia. Opera mediante líderes o asesoras de lactancia; también genera y difunde información, y organiza un congreso anual sobre lactancia materna.

7 Es decir, se durmió un rato. 


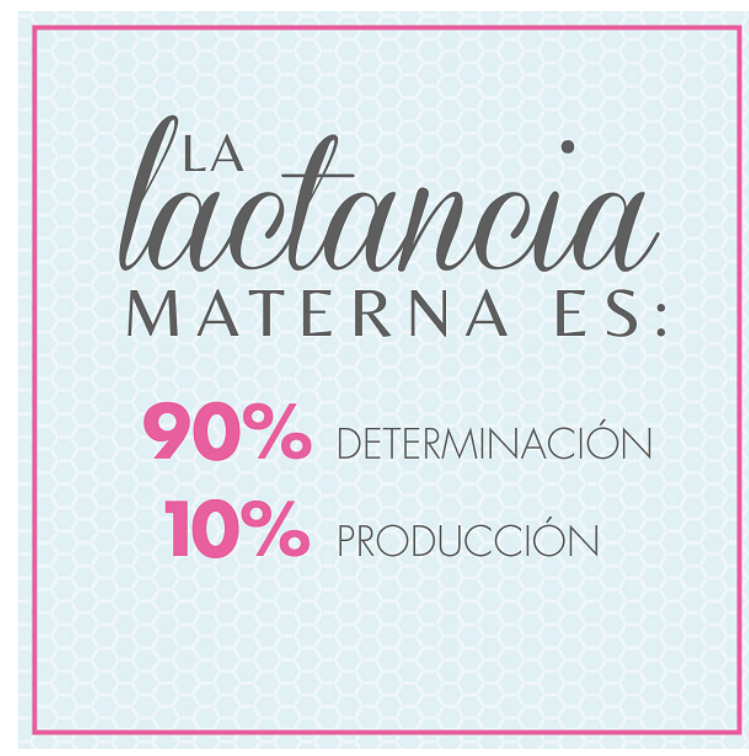

- Imagen 1. Cartel de promoción de la lactancia materna que sostiene la idea de que todas las mujeres puedan amamantar.

Sin embargo, algunas de mis interlocutoras me contaron - anteponiendo en muchas ocasiones un "es la primera vez que se lo digo a alguien"- que esta idea las presionaba mucho porque "en verdad, en verdad, en verdad, no tenía leche" (entrevista con Paola, Ciudad de México, mayo de 2018).

La idea de que todas las mujeres producen leche materna suficiente para alimentar a la cría, de acuerdo con las experiencias que me fueron narradas, no parece ser cierta. Éste es un punto ciego en los debates sobre lactancia materna, pues las posturas se dividen entre quienes piensan que sí es posible pero es cuestión de paciencia y determinación, y quienes piensan que no es posible y perciben como un ataque el hecho de que se sostenga que siempre se puede. Para estas últimas, la propuesta de tener paciencia hasta que la cría entienda que la leche saldrá mientras más succione no es funcional. Este grupo es más nutrido de lo que parece porque, según mis interlocutoras, muchas combinan la leche materna con la fórmula.

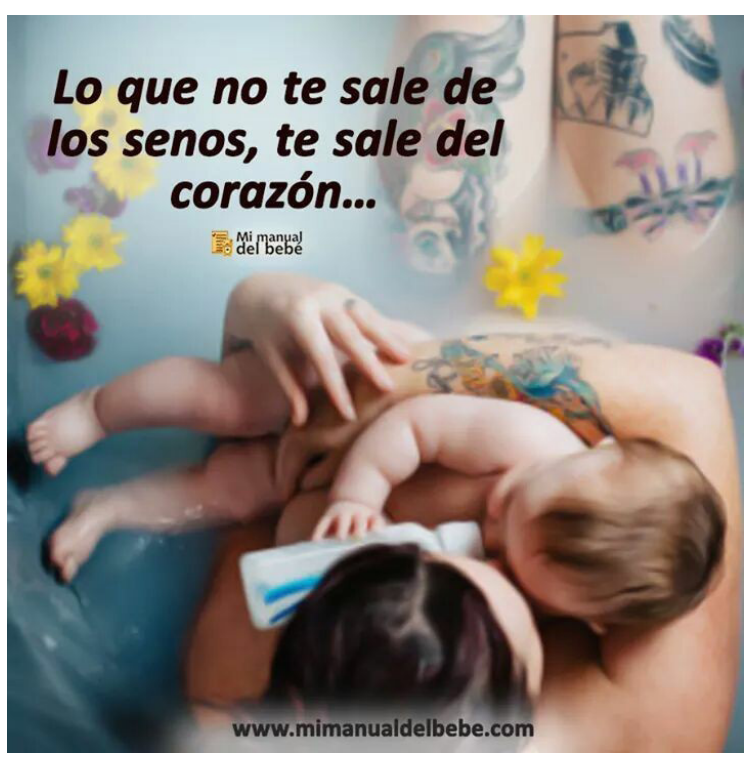

- Imagen 2. Cartel que afirma que el vínculo afectivo con el bebé no depende exclusivamente del amamantamiento.

En este sentido, y en contraste con la imagen 1, en el grupo "Madres de mamila" se compartían imágenes que aludían a que el amor y el vínculo con la criatura no depende del amamantamiento (véase la imagen 2).

Una vez más, el papel de las emociones es fundamental en las ideas y prácticas de ser madre y ser mujer. En este caso, el amor moviliza frente a la culpa que los discursos pro lactancia muchas veces sostienen de manera involuntaria.

Frente a las dificultades, algunas de mis interlocutoras decidieron dejar de sentirse mal, dieron por terminada la lactancia y sustituyeron la leche materna por fórmula láctea. Sin embargo, pasó tiempo antes de que pudieran liberarse de la culpa. Para otras, el momento del destete fue una liberación muy grande. Otras más decidieron que continuarían lactando por diversas razones, que también se relacionan con las emociones y con una postura política que reivindica el poder de las mujeres por medio de la maternidad y la crianza. En casos atípicos, la lactancia materna se 
convirtió en un método de sanación emocional muy importante para la mujer, como se observa en las dos narrativas siguientes:

Ahora, para mí, es muy lindo porque yo siento eso. En mí es mi forma de decirle al sistema, ¡toma! ¡Te vas a la mierda! Yo sí puedo. Esto no me lo quitas. Ahí, a veces, siento que como que otras, cuando tú dices eso, otras mujeres que no pudieron amamantar, se sienten como que tú las estas juzgando (entrevista con Romina, Ciudad de México, mayo de 2018).

Para mí, lactancia ha sido muy sanadora porque mi embarazo fue posible por ovodonación. Entonces, yo siempre sentí que no era la madre de Ana, y la lactancia me está permitiendo sanar esa idea de que mi cuerpo no sirve y de que no soy la madre biológica. ¿Acaso mi sangre, mi carne, mi leche no son biológicos? No son un huevo, pero son cuerpo (entrevista con Estela, Ciudad de México, abril de 2018).

Como podemos observar, las emociones atraviesan y nutren todo el proceso de lactancia materna exclusiva, artificial o mixta. La idea de formación del vínculo entre madre y cría pasa por estas prácticas. No es un acto meramente biológico ni mucho menos mecanizado por el simple hecho de que los cuerpos de las mujeres tengan glándulas productoras de leche. Las experiencias emocionales de las mujeres son complejas y están mediadas por las representaciones y normativas de lo que debe ser una "buena madre".

\section{ADMINISTRACIÓN DEL TIEMPO Y LOS CUIDADOS}

La lactancia, de acuerdo con las experiencias de mis interlocutoras, es lo que organiza sus días desde que la criatura nace. El sueño, el baño, las conversaciones con otras personas, los paseos, los espacios que habitan, están definidos en relación con los tiempos de la leche:

Yo entiendo, y realmente comprendo, por qué es tan difícil amamantar, o sea, lo estoy haciendo y sé por qué es difícil amamantar, lo vivo todos los días. Además, soy una mamá que trabajo. Me tengo que conectar a la puta máquina esa, antes cuatro veces al día, después tres y ahora dos. Todos los días me tengo que hacer eso para poder mandarle la leche a la guardería. Es doble trabajo. Porque además de hacer mi trabajo tengo que hacer otro trabajo, que es sacarme la leche para alimentar al bebé. A veces, otras mujeres que no amamantan, no nos reconocen a las mamás que amamantamos lo difícil que es y el trabajo que hacemos para poder lograrlo (entrevista con Romina, Ciudad de México, mayo de 2018).

En esta narrativa se nota con claridad el trabajo y la inversión de tiempo que implica sacarse la leche. También podemos darnos cuenta de que esta práctica implica la adquisición de artefactos para llevar a cabo la tarea economizando lo más posible el tiempo y el esfuerzo de la mujer. Por lo tanto, de la calidad del sacaleches depende el ahorro de tiempo en la extracción de la cantidad de leche requerida. Esto puede ser sumamente complicado para muchas mujeres en el contexto de esta investigación, por los costos de dichos artefactos. ${ }^{8}$

Por otra parte, también se observa un marcador identitario relevante: las mamás que no amamantan frente a las que sí amamantan. En este sentido, se expresa un reclamo de reconocimiento por el trabajo que hacen las que sí amamantan. Esto es bastante

8

Un sacaleches manual de buena calidad tiene un costo aproximado de 600 pesos mexicanos -30 dólares- y un sacaleches eléctrico doble tiene un costo de 1200 a 4000 pesos -de 60 a 200 dólares-. 


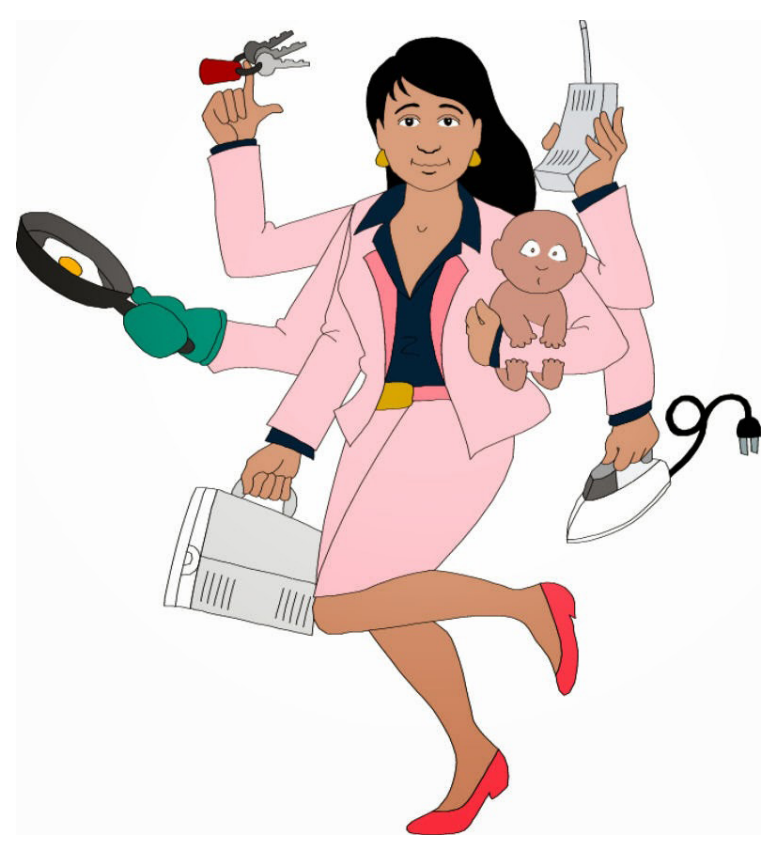

- Imagen 3. Caricatura que idealiza la representación de la madre trabajadora.

frecuente. En relación con esta práctica, en los grupos de Facebook que presento en este texto la caracterización de las madres que amamantan y las madres de mamila es muy visible. Desde mi punto de vista, esta distinción permite diferenciar por tipos a las madres y a las mujeres: las que amamantan $y$ las que no amamantan; las que trabajan y las que no lo hacen o no lo hacen tanto; cuando en realidad, en las narrativas de mis interlocutoras, el trabajo es el elemento común a todas las experiencias de lactancia, ya sea materna o artificial, y de ello depende, la necesidad de administrar el tiempo de la vida cotidiana.

En los dos grupos de Facebook se comparten imágenes que idealizan la representación de la madre trabajadora, tanto dentro como fuera del hogar. Se comparten con humor, y los comentarios casi siempre son de admiración e incluso dan lugar a discursos normativos sobre cómo debe ser una madre en la actualidad (véanse las imágenes 3 y 4).

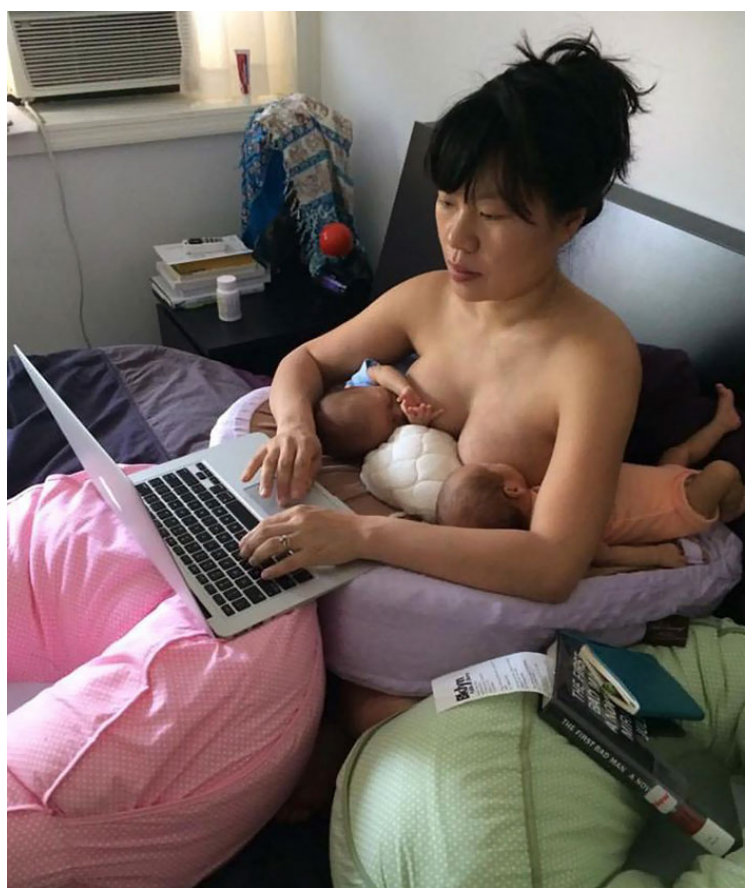

- Imagen 4. Imagen de madre trabajadora amamantando.

Muchas veces estas imágenes son la base para emitir opiniones que juzgan las distintas maneras de concebir y vivir la experiencia de la lactancia, la crianza y la maternidad en general. Por ejemplo, es frecuente encontrar comentarios en los que se pregunta: ¿y tú qué excusa tienes para no amamantar?; ¿cuál es el impedimento para que tú, además de trabajar, puedas dedicarte a las tareas del hogar? Son pocos los comentarios reflexivos en este sentido. Se asume como natural que las mujeres se dediquen a estos trabajos, y cuando no es así, parece haber una resignación al orden masculino del mundo laboral. Las mujeres suelen ser las que modifican sus rutinas para poder cumplir con la demanda del trabajo doméstico y extradoméstico.

Este proceso se va transformando conforme la criatura crece y se espacian las tomas, y también por los arreglos que las mujeres y sus parejas hagan para repartirse las tareas domésticas y de cuidados, aunque en la mayoría de los casos estas tareas recaen 
sobre las mujeres, debido a que los hombres suelen trabajar en instituciones que exigen jornadas largas. ${ }^{9}$ Entonces, es frecuente que la mujer tome toda la responsabilidad porque "no tiene caso que ambos duerman mal" (entrevista con Ana, Tepoztlán, Morelos, abril de 2018). Cuando los hombres tienen trabajos de jornadas más cortas o trabajo en casa, la participación es mayor, pero las mujeres siempre son las responsables primarias de la alimentación y la organización del hogar:

Es muy chistoso porque siempre tuvimos una relación tremendamente igualitaria y en el minuto en que nace un bebé eso se rompe, y la lactancia tiene todo que ver con esa ruptura porque finalmente él no le tiene que dar de comer. Las primeras veces él quería ser muy solidario y se levantaba en la noche conmigo. Y pues yo le decía: "pa' qué te levantas, pues mejor que pueda dormir uno". Estaba así como medio destartalado, y al día siguiente tenía que ir a trabajar y estaba hecho mierda, porque había pasado toda la noche conmigo. Nos ayudó mucho ese momento en que empezamos a poder darle de comer, la podía yo dejar cuatro horas e irme a una presentación de un libro o a una conferencia, y que se pudiera quedar con él y que él pudiera ser su cuidador, tanto como lo soy yo en otros momentos. Entonces como que la posibilidad de sacar leche y poder darle en botella nos abrió un poco ese campo (entrevista con Estela, Ciudad de México, abril de 2018).

Las mujeres que dieron lactancia mixta — leche materna y fórmula - o sólo fórmula muestran mayor libertad en el uso de su tiempo, aunque esto no necesariamente las libera del trabajo doméstico y extradoméstico. Para ellas, no hizo falta sacarse tanta leche ni llevar a cabo toda la labor de empaquetado, guardado y utilización del banco de leche. Para las que practicaron la lactancia artificial ni siquiera fue indispensable poner a disposición su propio cuerpo, tiempo y trabajo para alimentar a la criatura. En estos casos, lo común es que la madre de la mujer se haga cargo de los cuidados mientras ella lleva a cabo otras actividades. En general, ni las parejas, ni los padres, ni las suegras alimentan a las criaturas. Sin embargo, a veces se opta por estas formas de alimentación por presiones externas, como la necesidad de volver al trabajo y la imposibilidad de exigir el respeto de un derecho que está legislado:

Yo tenía mi permiso de maternidad. Pero mi jefe quería que regresara a trabajar. Me faltaba un mes y medio y me hablaba a cada rato, y la verdad sí me amenazó. Me dijo que iba a perder mi trabajo. Yo, del estrés, ni estaba a gusto. Mi mamá me llevaba al niño a la oficina para darle de comer. Pero era muy incómodo. Cuando empecé a darle la fórmula sentí un gran alivio. Pero sí, te sientes culpable (entrevista con Rubí, Cuautla, Morelos, marzo de 2018).

La relación con su propio cuerpo también está marcada por el tiempo y el proceso de lactancia. Las mujeres que amamantan mostraron, en general, cierto disgusto con algunos cambios en su cuerpo, como la pérdida de volumen y firmeza de los pechos. Algunas de ellas mencionaron que la familia o las amigas les insistían para que dieran pecho a sus hijos y trataban de incentivarlas hablándoles de que con ello perderían el peso acumulado durante el embarazo. Algunas, sobre todo las que están a favor de la lactancia exclusiva, aseguraron que esto era cierto. Otras dijeron que no, y al contrario que otras, afirmaron que nunca se habían sentido tan a disgusto con su cuerpo, tanto por el peso como por su forma y sus olores:

9

Todas mis interlocutoras han hecho pareja con hombres y han compartido con ellos la crianza, aunque algunas de ellas involucran a miembros de su familia de origen, como la madre y las hermanas. 
Es horrible. Yo nunca me había sentido tan mal. Tan gorda. Las chichis gigantes. Hueles a guácara todo el tiempo y no puedes decir nada porque todo mundo te juzga. Mi ropa era espantosa. Yo fui la más feliz el día que mi hija ya no quiso el pecho. No le insistí ni tantito (entrevista con Paola, Ciudad de México, mayo de 2018).

La relación con el cuerpo se transforma durante la lactancia: "sientes que tu cuerpo no te pertenece, eres una productora de leche, una vaca" (entrevista con Lilia, Cuautla, Morelos, marzo de 2018); el cuerpo "deja de pertenecerte" porque "vives sólo para producir leche y para alimentar a tu bebé" (entrevista con Paola, Ciudad de México, mayo de 2018). La mayoría comentó que cuando dejó de amamantar sintió que su cuerpo le pertenecía otra vez: su ropa le quedaba de nuevo, se vestía diferente, "sin botones de frente", olía distinto, podía comer lo que quisiera y descansar un poco más porque la criatura dormía más horas durante la noche. Para otras, dejar la lactancia fue un evento triste porque dejaron de estar "ligadas" a su cría; sin embargo, al poder dedicarse a otras actividades, se sintieron reconfortadas con el paso del tiempo.

\section{EL VÍNCULO}

Otro de los elementos que se asocian a la lactancia materna es la formación del vínculo afectivo entre la madre y su cría. No sólo importa la nutrición del infante sino el lazo aparentemente natural que se forma por medio de esta práctica y que le permite al infante estar protegido, ser amado y feliz.

En gran parte por esta idea algunas de mis interlocutoras estaban interesadas en la lactancia materna. Tenían miedo de que no se formara el vínculo del que tanto se habla si le daban fórmula o su propia leche en mamila al bebé. Sin embargo, en sus narrativas mostraron una postura crítica y reflexiva en relación con ello:

La lactancia es sólo una de las cosas que te vincula con tu bebé, y es bonito cuando ya lograste estar cómoda, o más o menos cómoda, pero no es lo único. Para nosotras, el momento de dormir es precioso. Nos abrazamos, nos vemos a los ojos, nos acariciamos. Definitivamente, la lactancia no es la que produce el vínculo (entrevista con Lucía, Ciudad de México, abril de 2018).

¡Ay, para nada! Hay mil cosas. De hecho, depende de las personalidades de la niña y tuya. Yo no sé muy bien jugar con ella, entonces platicamos mucho. Ha sido más grande que me he vinculado de manera más profunda. Pero iputa!, si dices eso, te comen (entrevista con Paola, Ciudad de México, mayo de 2018).

No creo. Yo más que por el vínculo lo hice porque era mi derecho, porque es la mejor opción de nutrición, porque pude y porque no quería darle al sistema también eso (entrevista con Romina, Ciudad de México, mayo de 2018).

Para mí, sí ha sido muy importante, por el tema de la ovodonación. Pero no creo que sea porque la lactancia es natural y entonces a todas les pasa lo mismo, sino por el significado que le estoy dando y le quiero dar. Me está sanando. Mira, eso no lo había pensado así (entrevista con Estela, Ciudad de México, abril de 2018).

La idea de que el vínculo entre madre e hijo se crea únicamente por medio de la lactancia materna es una de las más poderosas en este proceso social. Sin embargo, durante las entrevistas, tanto las mujeres que amamantan como las que no lo hacen reflexionaron sobre las múltiples formas en las que construyen vínculos con sus hijos. 


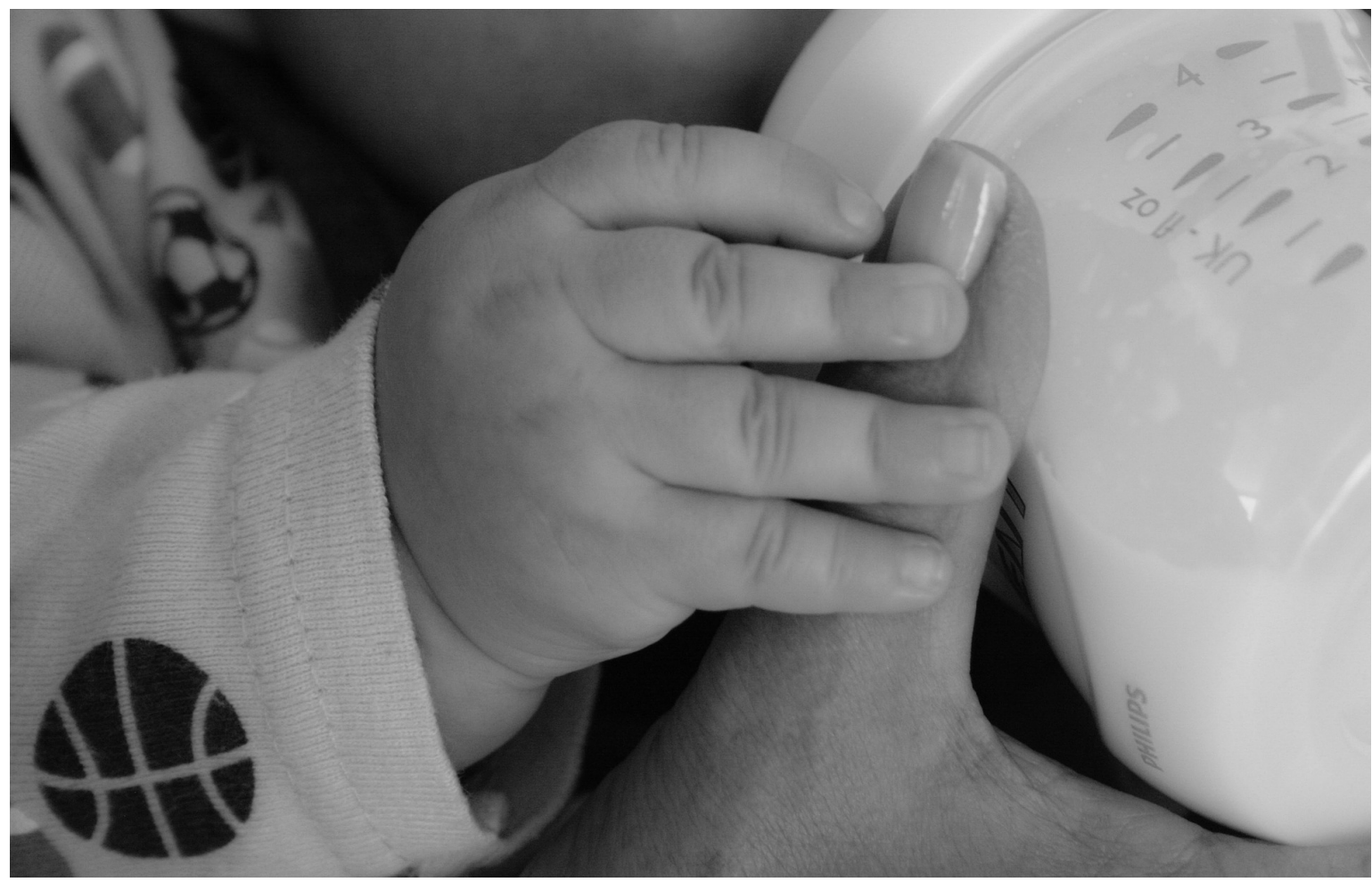

MARIAGARZON/PIXABAY • Lactancia con mamila.

\section{Consideraciones finales}

Es innegable el peso que tiene la alimentación en la mayoría de las sociedades. En muchas, la comida y su preparación está estrechamente vinculada a emociones como el amor, la tristeza, el enojo. De la emoción depende el gusto o el efecto del platillo. Las mujeres suelen ser las encargadas de alimentar a otros, aunque no siempre y no en todos los casos. Sin embargo, en el contexto de este estudio, ellas están a cargo de esta tarea en el ámbito familiar. Además, la lactancia materna es una práctica muy valorada debido a que la leche emana directamente del cuerpo de la madre a la cría, con toda la fragilidad humana que ésta representa. Nos alimentamos de nuestras madres para hacernos fuertes y esta idea tiene una potencia simbólica tremenda.
Entonces, como ocurre con cualquier otro platillo, las emociones de la madre pueden cambiar el gusto y las propiedades de la leche. Quizá por eso no se habla de las emociones de las mujeres cuando amamantan. Hacemos como que no existen, a menos que la emoción sea de alegría. ¿Cómo es posible que una madre no sienta una felicidad plena al alimentar con su propio cuerpo a su cría? La realidad es que este proceso social está lleno de emociones y no todas son positivas.

La culpa, la ansiedad y el amor movilizan para tomar decisiones y también para construir discursos y prácticas que distinguen a unas mujeres de otras. La lactancia materna tiene una carga simbólica particular y es insumo para la construcción de fronteras identitarias de género, la jerarquización de las experiencias de las mujeres y las tensiones en torno a los 
diversos discursos normativos sobre la maternidad. Al centrarnos en las experiencias y narrativas de las mujeres sobre la lactancia materna, ya sean positivas o negativas, podemos analizar la relación entre estructura social y agencia en contextos contemporáneos. Las decisiones que ellas toman en relación con la lactancia materna y sus cuerpos, movilizadas muchas veces por las emociones, están impregnadas de toda la carga simbólica de lo que una madre debe o no debe hacer.

Su identidad de género, entendida como la idea general pero a la vez muy particular que cada interlocutora tiene sobre ser mujer, se deja ver en estas narrativas y puede ser analizada con base en las categorías que aquí se propusieron. Las formas en las que cada una de estas mujeres asume su identidad y la relaciona con la maternidad, la relación de pareja y los cuidados, así como con otras dimensiones que consideran importantes como mujeres, marcan su relación con la lactancia, tanto en el presente como en retrospectiva. Las emociones en torno a esta experiencia se van transformando con el tiempo. Esta vivencia las constituye como sujetos sociales pertenecientes a un contexto sociohistórico particular. Desde esta perspectiva, la lactancia materna es un proceso social y no sólo un hecho biológico, por lo tanto, es objeto de estudio de la antropología y las ciencias sociales, dos disciplinas que se interesan en comprender las transformaciones de las experiencias en las sociedades contemporáneas.

\section{Bibliografía}

Ahmed, Sarah, 2015, La politica cultural de las emociones, Programa Universitario de Estudios de Género-Universidad Nacional Autónoma de México, México.

Bartlett, Alison, 2005, Breastwork, University of New South Wales Press, Sydney.

Boas, Franz, 1941, "Race, Language and Culture", en The Journal of Nervous and Mental Disease, vol. 94, núm. 4, pp. 513-514. Dol: $<10.1097 / 00005053-194110000-00062>$.

Boswell-Penc, Maia, 2006, Tainted Milk. Breastmilk, Feminisms and the Politics of Environmental Degradation, State University of New York Press, Albany.

Bourdieu, Pierre, 2002, La distinción, Taurus, México.

—_ 2006, “La identidad y la representación: elementos para una reflexión crítica sobre la idea de región”, en Ecuador Debate. Memorias de la Izquierda, núm. 67, pp. 165-184.

Butler, Judith, 2007, El género en disputa. El feminismo y la subversión de la identidad, Paidós Ibérica, Barcelona.

Cano, Gabriela, 2009, "Inocultables realidades del deseo", en Género, poder y política en el México posrevolucionario, Fondo de Cultura Económica/Universidad Autónoma Metropolitana, México, pp. 61-90

Chávez, Alicia Fedelina y Florence Guido-Dibrito, 1999, "Racial and Ethnic Identity and Development", en New Directions for Adult and Continuing Education, pp. 39-48. Dol: <10.1002/ace.8405>.

Dowling, Sally, Jennie Naidoo y David Pontin, 2012, "Breastfeeding in Public: Women's Bodies, Women's Milk”, en Paige Hall Smith, Bernice L. Hausman y Miriam Labbok (eds.), Beyond Health, Beyond Choice. Breastfeeding Constraints and Realities, Rutgers University Press, Nuevo Brunswick, pp. 249-258

Fearon, James D. y David D. Laitin, 2000, "Violence and the Social Construction of Ethnic Identity", en International Organization, vol. 54, núm. 4, pp. 845-877. DOI: <10.1162/002081800551398>.

Gatens, Moira, 2003, Imaginary Bodies: Ethics, Power and Corporeality, Taylor and Francis e-Library, Londres.

Giddens, Anthony, 1991, Modernity and Self-Identity. Self and Society in the Late Modern Age, Stanford University Press, Stanford.

Giménez, Gilberto, 2000, “'Identidades étnicas: estado de la cuestión”, en Leticia Reina (coord.), Los retos de la etnicidad en los Estadosnación del siglo XXI, México, Centro de Investigaciones y Estudios Superiores en Antropología Social/Instituto Nacional Indigenista/ Miguel Ángel Porrúa, pp. 45-70. 
2009, “Memoria, relatos e identidades urbanas”, en Versión, vol. 23, pp. 197-209.

González de Cossío, Teresita, Leticia Escobar-Zaragoza, Dinorah González-Castell y Juan A. Rivera-Dommarco, 2013, "Prácticas de alimentación infantil y deterioro de la lactancia materna en México”, en Salud Pública de México, núm. 55, supl. 2, pp. s170-s179.

González de Cossío, Teresita, Leticia Escobar-Zaragoza, Dinorah González-Castell, Teresa Shamah-Levy y Juan A. Rivera-Dommarco, 2014, "La lactancia materna exclusiva en menores de seis meses se asocia con un mejor peso para la longitud en hogares con inseguridad alimentaria en México", en Salud Pública de México, núm. 56, supl. 1, pp. s31-s38. Disponible en línea: <http://www.scielo.org.mx/scielo. php?script=sci_arttext\&pid=S0036-36342014000700006\&lng=es\&tIng=es>. Consultado el 5 de febrero de 2018.

Gorrita Pérez, Remigio Rafael, Yasnier Bárcenas Bellót, Yelina Gorrita Pérez y Belkis Brito Herrera, 2014a, "Estrés y ansiedad maternos y su relación con el éxito de la lactancia materna", en Revista Cubana de Pediatría, vol. 86, núm. 2. Disponible en línea: <http://scielo.sld.cu/ scielo.php?script=sci_arttext\&pid=S0034-75312014000200006\&lng=es\&tlng=es>. Consultado el 18 de octubre de 2018.

Gorrita Pérez, Remigio Rafael, Daily Brito Linares, Yenisley Ravelo Rodríguez y Elisa Ruiz Hernández, 2014b, "Embarazo deseado y planificado, lactancia previa, aptitud para lactar y conocimientos de las madres sobre lactancia”, en Revista Cubana de Pediatría, vol. 86, núm. 3, pp. 289-297. Disponible en línea: <http://scieloprueba.sld.cu/scielo.php?script=sci_arttext\&pid=S0034-75312014000300003\&lng=es\&t Ing=es>. Consultado el 3 de enero de 2019.

Gorrita Pérez, Remigio Rafael, Alcira Terrazas Saldaña, Dailin Brito Linares y Yenisley Ravelo Rodríguez, 2015, "Algunos aspectos relacionados con la lactancia materna exclusiva en los primeros seis meses de vida”, en Revista Cubana de Pediatría, vol. 87, núm. 3, pp. 285-297. Disponible en línea: <http://scieloprueba.sld.cu/scielo.php?script=sci_arttext\&pid=S0034-75312015000300004\&lng=es\&tIng=es>.

Gutiérrez, Ana Paulina, 2015, Identidades trans femeninas. Sociabilidades, internet, narrativas y tránsitos de género en la Ciudad de México, tesis de doctorado en ciencia social con especialidad en sociología, Centro de Estudios Sociológicos-El Colegio de México, México.

Gutiérrez, Juan Pablo, Juan Rivera-Dommarco, Teresa Shamah-Levy, Salvador Villalpando-Hernández, Aurora Franco, Lucía Cuevas-Nasu y Mauricio Hernández-Ávila, 2012, Encuesta Nacional de Salud y Nutrición 2012. Resultados nacionales, Instituto Nacional de Salud Pública, Cuernavaca.

Hurst, Carol Grace, 2012, "Sexual or Maternal Breasts? A Feminist View of the Contested Right to Breastfeed Publicly", en Paige Hall Smith, Bernice L. Hausman y Miriam Labbok (eds.), Beyond Health, Beyond Choice. Breastfeeding Constraints and Realities, Rutgers University Press, Nuevo Brunswick, pp. 259-268.

Koerber, Amy, 2013, Breast or Bottle. Contemporary Controversies in Infant-Feeding Policy and Practice, University of South Caroline Press, Columbia.

Leon-Cava, Natalia, Chessa Lutter, Jay Ross y Luann Martin, 2002, Quantifying the Benefits of Breastfeeding: A Summary of the Evidence, The Linkages Project/Pan American Health Organization, Washington, D. C. Disponible en línea: <https://www.paho.org/hq/ dmdocuments/2011/benefitsLM.pdf>. Consultado el 7 de noviembre 2017.

Lubold, Amanda y Louise Marie Roth, 2012, "The Impact of Workplace Practices on Breastfeeding Experiences and Disparities Among Women”, en Paige Hall Smith, Bernice L. Hausman y Miriam Labbok (eds.), Beyond Health, Beyond Choice. Breastfeeding Constraints and Realities, Rutgers University Press, Nuevo Brunswick, pp. 157-167.

Lucas, Jennifer y Deborah McCarter-Spaulding, 2012, “Working out Work: Race, Employment and Public Policy”, en Paige Hall Smith, Bernice L. Hausman y Miriam Labbok (eds.), Beyond Health, Beyond Choice. Breastfeeding Constraints and Realities, Rutgers University Press, Nuevo Brunswick, pp. 144-156.

McTeer, Heather, 2012, "Fat, Young, and Poor: Why Breastfeeding is a Critical Weapon in the Fight Against Childhood Obesity", en Breastfeed Medicine: The Official Journal of the Academy of Breastfeeding Medicine, vol. 7, núm. 5, pp. 325-326. Dol: <10.1089/bfm.2012.0073>.

Núñez Pineda, Christian Michelle, José Vicente Franco Soto y Marco Antonio Labrador R., 2017, "Impacto del lactario domiciliario en madres trabajadoras. Hospital Central de San Cristóbal”, en Archivos Venezolanos de Puericultura y Pediatría, vol. 80, núm. 1, pp. 10-14.

Pino V., José Luis, Miguel Ángel López E., Andrea Pilar Medel I. y Alejandra Ortega S., 2013, “Factores que inciden en la duración de la lactancia materna exclusiva en una comunidad rural de Chile", en Revista Chilena de Nutrición, vol. 40, núm. 1, pp. 48-54. Disponible en línea: <https://dx.doi.org/10.4067/S0717-75182013000100008>.

Sanders, Jimy M., 2002, "Ethnic Boundaries and Identity in Plural Societies", en Annual Review of Sociology, vol. 28, pp. 327-357. Dol: $<10.2307 / 3069245>$ 
Scott, Joan Wallach, 2008, "El género como categoría útil para el análisis histórico", en Género e historia, Fondo de Cultura Económica/ Universidad Autónoma de la Ciudad de México, México, pp. 48-75.

Stryker, Susan, 2008, Transgender History, Seal Press, Berkeley.

Valentine, David, 2014, "Identity”, en Transgender Studies Quarterly, vol. 1, núms. 1-2, pp. 103-106.

Wolf, Joan, 2011, Is Breast Best? Taking on the Breastfeeding Experts and the New High Stakes of Motherhood, New York University Press, Nueva York.

\section{Entrevistas}

Ana, Tepoztlán, Morelos, abril de 2018.

Estela, Ciudad de México, abril de 2018.

Gabriela, Ciudad de México, mayo de 2018.

Lilia, Cuautla, Morelos, marzo de 2018.

Lucía, Ciudad de México, abril de 2018.

Magda, Tepoztlán, Morelos, marzo de 2018.

Paola, Ciudad de México, mayo de 2018.

Romina, Ciudad de México, mayo de 2018.

Rubí, Cuautla, Morelos, marzo de 2018. 